$03,04,19$

\title{
Высокотемпературная теплоемкость титанатов самария и эрбия со структурой пирохлора
}

\author{
(С) Л.Т. Денисова ${ }^{1}$, Л.Г. Чумилина ${ }^{1}$, В.М. Денисов ${ }^{1}$, В.В. Рябов ${ }^{2}$ \\ ${ }^{1}$ Институт цветных металлов и материаловедения Сибирского федерального университета, \\ Красноярск, Россия \\ ${ }^{2}$ Институт металлургии УрО РАН, \\ Екатеринбург, Россия \\ E-mail: antluba@mail.ru
}

(Поступила в Редакцию 11 апреля 2017 г.)

\begin{abstract}
Методом твердофазного синтеза на воздухе из стехиометрических смесей $\mathrm{Sm}_{2} \mathrm{O}_{3}\left(\mathrm{Er}_{2} \mathrm{O}_{3}\right)-\mathrm{TiO}_{2}$ последовательно при температурах 1673 и $1773 \mathrm{~K}$ получены титанаты $\mathrm{Sm}_{2} \mathrm{Ti}_{2} \mathrm{O}_{7}$ и $\mathrm{Er}_{2} \mathrm{Ti}_{2} \mathrm{O}_{7}$ со структурой пирохлора. Методом дифференциальной сканирующей калориметрии измерена высокотемпературная теплоемкость оксидных соединений. По экспериментальным зависимостям $C_{p}=f(T)$ рассчитаны их термодинамические свойства.
\end{abstract}

Работа выполнена при финансовой поддержке работ, выполняемых в рамках Государственного задания Министерства образования и науки Российской Федерации Сибирскому федеральному университету на 2017-2019 (проект 4.8083.2017/БЧ „Формирование банка данных термодинамических характеристик сложнооксидных полифункциональных материалов, содержащих редкие и рассеянные элементы“ $)$.

DOI: 10.21883/FTT.2017.12.45223.122

\section{1. Введение}

В течение длительного времени не ослабевает интерес к сложным оксидным соединениям со структурой пирохлора [1-5]. Обусловлено это возможностями их практического применения в различных областях науки и техники $[1,4,6-8]$. К подобным материалам относятся и титанаты $\mathrm{Sm}_{2} \mathrm{Ti}_{2} \mathrm{O}_{7}$ и $\mathrm{Er}_{2} \mathrm{Ti}_{2} \mathrm{O}_{7}$ [1-3]. Для них имеются данные о получении нано- $[6,7]$ и монокристаллов [9], структуре [1-3], магнитных [10] и электрофизических [11] свойствах. В то же время сведения о теплофизических свойствах практически отсутствуют. Имеются лишь данные об энтальпии образования $[12,13]$ и теплоемкости $\mathrm{Er}_{2} \mathrm{Ti}_{2} \mathrm{O}_{7}$ при очень низких температуpax $[14,15]$. Отметим, что измерение теплоемкости один из путей определения теплофизических и термодинамических свойств синтезируемых твердофазных материалов [16].

Целью настоящей работы является исследование высокотемпературной теплоемкости титанатов $\mathrm{Sm}_{2} \mathrm{Ti}_{2} \mathrm{O}_{7}$ и $\mathrm{Er}_{2} \mathrm{Ti}_{2} \mathrm{O}_{7}$ и определение по этим данным термодинамических свойств оксидных соединений со структурой пирохлора.

\section{2. Эксперимент}

Учитывая, что как исходные оксиды, так и $\mathrm{Sm}_{2} \mathrm{Ti}_{2} \mathrm{O}_{7}$ и $\mathrm{Er}_{2} \mathrm{Ti}_{2} \mathrm{O}_{7}$ имеют высокие температуры плавления [1], титанаты самария и эрбия получали твердофазным методом. Предварительно прокаленные при $1173 \mathrm{~K}$ исходные оксиды $\left(\mathrm{Sm}_{2} \mathrm{O}_{3}\right.$ (99.99\%), $\mathrm{Er}_{2} \mathrm{O}_{3}$ и $\mathrm{TiO}_{2}$ (ос. ч)) в стехиометрических соотношениях перетирали в ага- товой ступке и прессовали в таблетки. Их обжигали на воздухе последовательно при следующих условиях: 1) $1673 \mathrm{~K}(3 \mathrm{~h})+1773 \mathrm{~K}(1 \mathrm{~h})$; 2) $1673 \mathrm{~K}(1 \mathrm{~h})+1773 \mathrm{~K}(3 \mathrm{~h})$; 3) $1673 \mathrm{~K}(1 \mathrm{~h})+1773 \mathrm{~K}(4 \mathrm{~h})$; 4) $1773 \mathrm{~K}(5 \mathrm{~h})$. Для достижения полного твердофазного взаимодействия реагентов после каждого цикла проводили перетирание спеченных образцов с последующим прессованием. Фазовый состав синтезированных образцов контролировали с использованием рентгенофазового анализа (дифрактометр XPert Pro MPD фирмы „PANalytical“) в излучении $\mathrm{Cu} K_{\alpha}$. Регистрация выполнялась высокоскоростным детектором PIXcel с графитовым монохроматором в угловом интервале $2 \theta=14-124^{\circ}$ с шагом $0.013^{\circ}$. Полученные результаты показаны на рис. 1 и 2. Параметры решетки определены путем полнопрофильного уточнения методом минимизации производной разности [17].

Измерение теплоемкости $C_{p}$ синтезированных титанатов проводили методом дифференциальной сканирующей калориметрии на приборе STA 449 C Jupiter (NETZSCH). Методика экспериментов описана ранее $[18,19]$. Полученные данные обрабатывались с помощью пакета анализа NETZSCH Proteus Thermal Analysis и лицензионного программного инструмента Sistat Sigma Plot 12.

\section{3. Результаты и их обсуждение}

Параметры элементарной ячейки $\mathrm{Sm}_{2} \mathrm{Ti}_{2} \mathrm{O}_{7}$ (пр.гр. $F d 3 m, V=1069.92(2) \AA^{3}$ ) и $\operatorname{Er}_{2} \mathrm{Ti}_{2} \mathrm{O}_{7}$ (пр.гр. $F d 3 m$, $V=1022.51(2) \AA^{3}$ ) в сравнении с данными других авторов приведены в табл. 1, из которой следует, что наши 


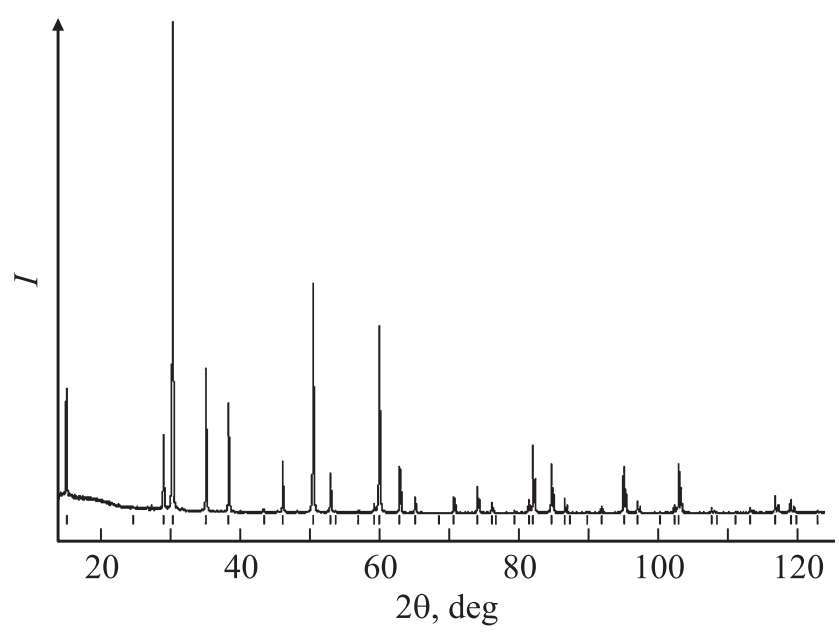

Рис. 1. Дифрактограмма $\mathrm{Sm}_{2} \mathrm{Ti}_{2} \mathrm{O}_{7}$ при комнатной температуре.

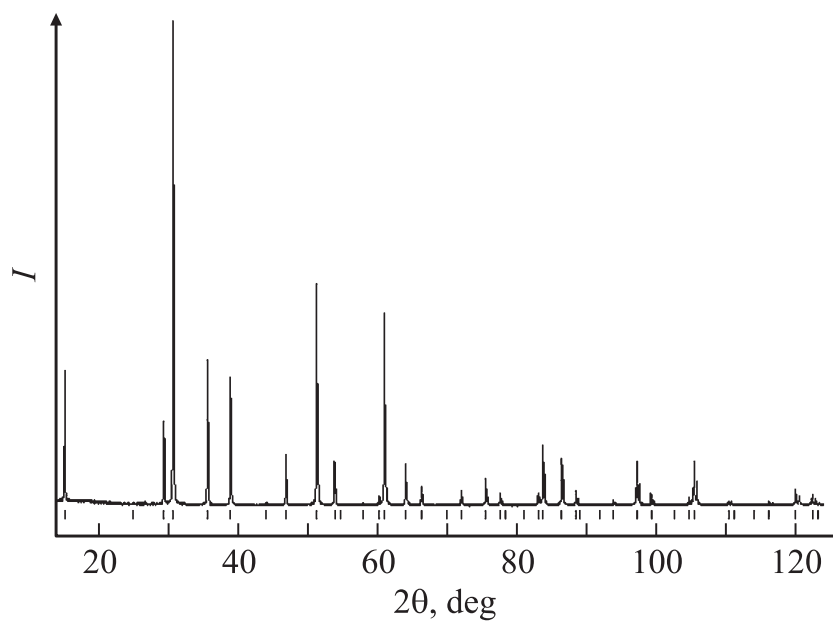

Pис. 2. Дифрактограмма $\mathrm{Er}_{2} \mathrm{Ti}_{2} \mathrm{O}_{7}$ при комнатной температуре.

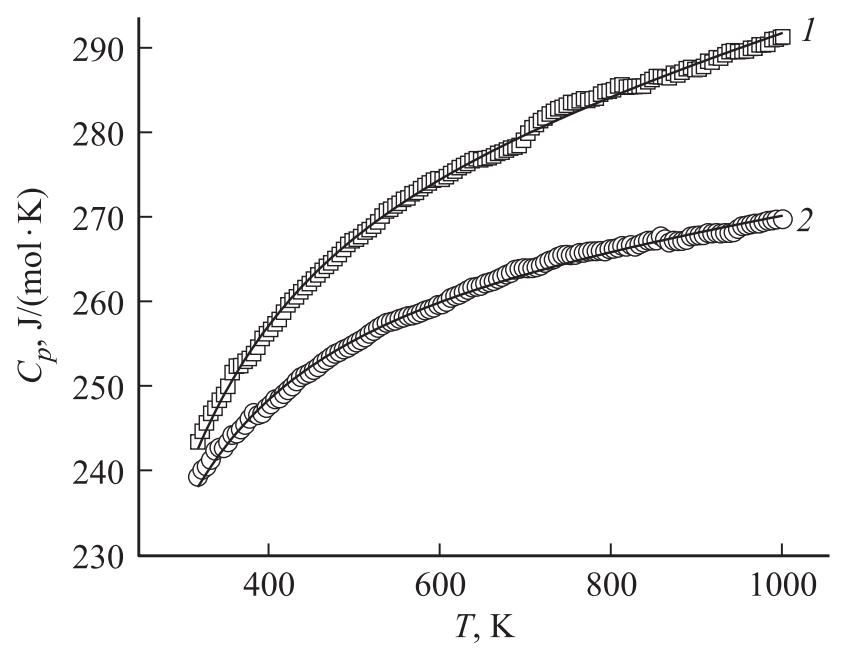

Рис. 3. Температурная зависимость молярной теплоемкости $\mathrm{Sm}_{2} \mathrm{Ti}_{2} \mathrm{O}_{7}$ (1) и $\mathrm{Er}_{2} \mathrm{Ti}_{2} \mathrm{O}_{7}(2)$.
Таблица 1. Параметры элементарных ячеек $\mathrm{Sm}_{2} \mathrm{Ti}_{2} \mathrm{O}_{7}$ и $\mathrm{Er}_{2} \mathrm{Ti}_{2} \mathrm{O}_{7}$

\begin{tabular}{c|c|l|c}
\hline \multicolumn{2}{c|}{$\mathrm{Sm}_{2} \mathrm{Ti}_{2} \mathrm{O}_{7}$} & \multicolumn{2}{c}{$\mathrm{Er}_{2} \mathrm{Ti}_{2} \mathrm{O}_{7}$} \\
\hline$a, \AA$ & Лит. ссылка & \multicolumn{1}{|c}{$a, \AA$} & Лит. ссылка \\
\hline 10.211 & {$[1]$} & 10.07 & {$[1]$} \\
10.227 & {$[3]$} & 10.073 & {$[3]$} \\
10.239 & {$[3]$} & 10.085 & {$[3]$} \\
10.238 & {$[3]$} & 10.076 & {$[3]$} \\
10.211 & {$[4]$} & 10.060 & {$[4]$} \\
$10.1996(51)$ & {$[7]$} & $10.0450(54)$ & {$[7]$} \\
$10.234(4)$ & {$[11]$} & 10.075 & {$[10]$} \\
$10.1933(6)$ & {$[12]$} & $10.0840(2)$ & {$[12]$} \\
$10.2321(2)$ & {$[20]$} & $10.077044(1)$ & {$[21]$} \\
$10.2278(1)$ & Наст. работа & $10.0745(1)$ & Наст. работа
\end{tabular}

результаты достаточно близки известным значениям параметров решетки.

Влияние температуры на теплоемкость $\mathrm{Sm}_{2} \mathrm{Ti}_{2} \mathrm{O}_{7}$ и $\mathrm{Er}_{2} \mathrm{Ti}_{2} \mathrm{O}_{7}$ показано на рис. 3. Видно, что с ростом температуры значения $C_{p}$ закономерно увеличиваются. На зависимостях $C_{p}=f(T)$ отсутствуют разного рода экстремумы. Полученные значения $C_{p}$ могут быть описаны уравнением Майера-Келли

$$
\begin{aligned}
-\mathrm{Sm}_{2} \mathrm{Ti}_{2} \mathrm{O}_{7} & \\
C_{p}=(265.44 \pm 0.51) & +(29.7 \pm 0.5) \cdot 10^{-3} T \\
& -(32.23 \pm 0.52) \cdot 10^{5} T^{-2}, \\
-\mathrm{Er}_{2} \mathrm{Ti}_{2} \mathrm{O}_{7} & \\
C_{p}=(258.06 \pm 0.51)+ & +(14.58 \pm 0.60) \cdot 10^{-3} T \\
& -(25.09 \pm 0.49) \cdot 10^{5} T^{-2} .
\end{aligned}
$$

Коэффициенты корреляции уравнений (1) и (2) соответственно равны 0.9982 и 0.9979.

С использованием уравнений (1) и (2) по известным термодинамическим соотношениям рассчитаны изменения энтальпии $H^{0}(T)-H^{0}(320 \mathrm{~K})$, энтропии $S^{0}(T)-S^{0}(320 \mathrm{~K})$ и приведенной энергии Гиббса $\Phi^{0}(T)$. Эти результаты приведены в табл. 2.

Из табл. 2 следует, что для $\mathrm{Sm}_{2} \mathrm{Ti}_{2} \mathrm{O}_{7}$ при температурах выше $600 \mathrm{~K}$ значения $C_{p}$, полученные нами, превышают классический предел Дюлонга-Пти $3 R s$, где $R$ - универсальная газовая постоянная, $s-$ число атомов в формульной единице оксида. В то же время для $\mathrm{Er}_{2} \mathrm{Ti}_{2} \mathrm{O}_{7}$ значения $C_{p}$ его не превышают.

С использованием найденных нами значений характеристической температуры Дебая $\left(\Theta_{\mathrm{D}}=510 \mathrm{~K}\right.$ для $\mathrm{Sm}_{2} \mathrm{Ti}_{2} \mathrm{O}_{7}, \Theta_{\mathrm{D}}=544 \mathrm{~K}$ для $\mathrm{Er}_{2} \mathrm{Ti}_{2} \mathrm{O}_{7}$ ), которые определялись аналогично [22] по соотношению

$$
C_{p}=s D\left(\frac{\Theta_{\mathrm{D}}}{T}\right),
$$

где $D\left(\Theta_{\mathrm{D}} / T\right)$ - функция Дебая [23], были рассчитаны $C_{p}$. При этом считалось, что в первом приближе- 
Таблица 2. Термодинамические свойства $\mathrm{Sm}_{2} \mathrm{Ti}_{2} \mathrm{O}_{7}$ и $\mathrm{Er}_{2} \mathrm{Ti}_{2} \mathrm{O}_{7}$

\begin{tabular}{|c|c|c|c|c|}
\hline$T, \mathrm{~K}$ & $\begin{array}{c}C_{p} \\
\mathrm{~J} /(\mathrm{mol} \cdot \mathrm{K})\end{array}$ & $\begin{array}{c}H^{0}(T)-H^{0}(320 \mathrm{~K}) \\
\mathrm{kJ} / \mathrm{mol}\end{array}$ & $\begin{array}{c}S^{0}(T)-S^{0}(320 \mathrm{~K}) \\
\mathrm{J} /(\mathrm{mol} \cdot \mathrm{K})\end{array}$ & $\begin{array}{c}\Phi^{0}(T) \\
\mathrm{J} /(\mathrm{mol} \cdot \mathrm{K})\end{array}$ \\
\hline \multicolumn{5}{|c|}{$\mathrm{Sm}_{2} \mathrm{Ti}_{2} \mathrm{O}_{7}$} \\
\hline $\begin{array}{r}320 \\
350 \\
400 \\
450 \\
500 \\
550 \\
600 \\
650 \\
700 \\
750 \\
800 \\
850 \\
900 \\
950 \\
1000\end{array}$ & $\begin{array}{l}243.5 \\
249.5 \\
257.2 \\
262.9 \\
267.4 \\
271.1 \\
274.3 \\
277.1 \\
279.7 \\
282.0 \\
284.2 \\
286.2 \\
288.2 \\
290.1 \\
291.9\end{array}$ & $\begin{array}{c}- \\
7.40 \\
20.08 \\
33.08 \\
46.35 \\
59.81 \\
73.45 \\
87.24 \\
101.2 \\
115.2 \\
129.4 \\
143.6 \\
158.0 \\
172.4 \\
187.0\end{array}$ & $\begin{array}{c}- \\
22.10 \\
55.94 \\
86.58 \\
114.6 \\
140.2 \\
163.9 \\
186.0 \\
206.6 \\
226.0 \\
244.3 \\
261.5 \\
278.0 \\
293.6 \\
308.5\end{array}$ & $\begin{array}{r}- \\
0.96 \\
5.75 \\
13.05 \\
21.83 \\
31.44 \\
41.50 \\
51.77 \\
62.11 \\
72.40 \\
82.57 \\
92.60 \\
102.4 \\
112.1 \\
121.5\end{array}$ \\
\hline \multicolumn{5}{|c|}{$\mathrm{Er}_{2} \mathrm{Ti}_{2} \mathrm{O}_{7}$} \\
\hline 320 & 238.2 & - & - & \\
\hline 350 & 242.7 & 7.22 & 21.55 & 0.94 \\
\hline 400 & 248.2 & 19.50 & 54.34 & 5.60 \\
\hline 450 & 252.2 & 32.01 & 83.82 & 12.68 \\
\hline 500 & 255.3 & 44.71 & 110.6 & 21.15 \\
\hline 550 & 257.8 & 57.54 & 135.0 & 30.14 \\
\hline 600 & 259.9 & 70.48 & 157.5 & 40.08 \\
\hline 650 & 261.6 & 83.52 & 178.4 & 49.93 \\
\hline 700 & 263.2 & 96.64 & 197.9 & 59.81 \\
\hline 750 & 264.5 & 109.8 & 216.1 & 69.62 \\
\hline 800 & 265.8 & 123.1 & 233.2 & 79.31 \\
\hline 850 & 267.0 & 136.4 & 249.3 & 88.85 \\
\hline 900 & 268.1 & 149.8 & 264.6 & 98.15 \\
\hline 950 & 269.1 & 163.2 & 279.1 & 107.3 \\
\hline 1000 & 270.1 & 176.7 & 293.0 & 116.3 \\
\hline
\end{tabular}

нии величины $C_{p}$ и $C_{v}$ близки. Установлено, что для $\mathrm{Er}_{2} \mathrm{Ti}_{2} \mathrm{O}_{7}$ рассчитанные и экспериментальные значения достаточно хорошо совпадают между собой (максимальное отклонение наблюдается в области $600 \mathrm{~K}$ и составляет $1.2 \%$ ). Для $\mathrm{Sm}_{2} \mathrm{Ti}_{2} \mathrm{O}_{7}$ такого соответствия не отмечено, поскольку, как отмечено выше, полученные значения $C_{p}$ превышают предел Дюлонга-Пти.

Следует отметить, что если станнаты $R_{2} \mathrm{Sn}_{2} \mathrm{O}_{7}$ представляют полную серию изоструктурных соединений со структурой пирохлора, тогда как для титанатов редкоземельных элементов этого не наблюдается $[1-3,5]$. Пирохлорные соединения $R_{2} \mathrm{Ti}_{2} \mathrm{O}_{7}$ существуют для редкоземельных элементов, ионные радиусы которых удовлетворяют условию $1.28<r_{R^{3+}} / r_{\mathrm{Ti}^{4+}} \leq 1.76$ [1]. Соединения $R_{2} \mathrm{Ti}_{2} \mathrm{O}_{7}(R=\mathrm{La}-\mathrm{Nd})$ кристаллизуются в моноклинной структуре $\left(r_{R^{3+}} / r_{\mathrm{T}^{4+}}<1.2\right)[1,3] . \mathrm{Sm}_{2} \mathrm{Ti}_{2} \mathrm{O}_{7}$ является первым соединение в ряду $\mathrm{Sm}-\mathrm{Lu}$ со структурой пирохлора. К тому же установлен переход кубической модификации $\mathrm{Sm}_{2} \mathrm{Ti}_{2} \mathrm{O}_{7}$ в моноклинную после выдержки при температуре $1663 \mathrm{~K}$ и давлении $5.4 \mathrm{GPa}$ [3], тогда как для других титанатов РЗЭ требуются более высокие давления [1]. Отношение $r_{R^{3+}} / r_{\mathrm{Ti}^{4+}}$ является одним из факторов, влияющих на величину области гомогенности титанатов $R_{2} \mathrm{Ti}_{2} \mathrm{O}_{7}$ [1]. Не исключено, что все это сказывается на особенности $C_{p}=f(T)$ для $\mathrm{Sm}_{2} \mathrm{Ti}_{2} \mathrm{O}_{7}$ и $\mathrm{Er}_{2} \mathrm{Ti}_{2} \mathrm{O}_{7}$.

\section{4. Заключение}

Исследована высокотемпературная теплоемкость титанатов $\mathrm{Sm}_{2} \mathrm{Ti}_{2} \mathrm{O}_{7}$ и $\mathrm{Er}_{2} \mathrm{Ti}_{2} \mathrm{O}_{7}$. Показано, что зависимости $C_{p}=f(T)$ хорошо описываются уравнением Майера-Келли. Отмечено, что для $\mathrm{Er}_{2} \mathrm{Ti}_{2} \mathrm{O}_{7}$ для описания теплоемкости хорошо применима теория Дебая. Рассчитаны термодинамические свойства оксидных соединений. 


\section{Список литературы}

[1] Л.Н. Комиссарова, В.М. Шацкий, Г.Я. Пушкина, Л.Г. Щербакова, Л.Г. Мамсурова, Г.Е. Суханова. Соединения редкоземельных элементов. Карбонаты, оксалаты, нитраты, титанаты. Наука, М. (1984). 235 с.

[2] Я.С. Рубинчик. Соединения двойных окислов редкоземельных элементов. Наука и техника, Минск (1974). 144 с.

[3] К.И. Портной, Н.И. Тимофеев. Кислородные соединения редкоземельных элементов. Металлургия, М. (1986). $480 \mathrm{c}$.

[4] М.Ф. Васильева, А.К. Герасюк, А.И. Гоев, В.В. Потелов, Б.Н. Сенник, А.Б. Сухачев, Б.М. Жигарновский, В.В. Кириленко, А.В. Ноздрачев. Прикл. физика 5, 91 (2007).

[5] А.В. Шляхтина. Кристаллография 58, 4, 545 (2013).

[6] L. Zhang, W. Zhang, J. Zhu, Q. Hao, C. Xu, X. Yang, L. Lu, X. Wang. J. Alloys Comp. 480, L45 (2009).

[7] W. Wang, L. Zhang, H. Zhong, L. Lu, Y. Yang, X. Wang. Mater. Characteriz. 61, 154 (2010).

[8] V.F. Zinchenko, V.I. Maksimenko, V.P. Sobol', L.V. Sadkovska, Ye.V. Timukhin, A.V. Bogatsky. CAOL. Int. Conf. Adv. Optoelectr. Laser. Sevastopol. (2010). 233 p.

[9] G. Balakrishnan, O.A. Petrenko, M.R. Lees. J. Phys.: Condens. Matter. 10, L.723 (1998).

[10] N. Ben Amor, M. Bejar, M. Hussein, E. Dhahri, M.A. Valente, E.K. Hlil. J. Supercond. Nov. Magn. 25, 1035 (2012).

[11] N. Cioatera, E.A. Voinea, E. Panaintescu, A. Rolle, S. Somacescu, C.I. Spinu, R.N. Vannir. Ceramics Int. 42, 1492 (2016).

[12] K.B. Helean, S.V. Ushakov, C.E. Brown, A. Navrotsky, J. Lian, R.C. Ewing, J.M. Farmer, L.A. Boatner. J. Solid State Chem. 177, 1858 (2004).

[13] A. Navrotsky, W. Lee, A. Mielewczyk-Gryn, S.V. Ushakov, A. Anderko, H. Wu, R.E. Riman. J. Chem Thermodyn. 88, 126 (2015).

[14] S.S. Sosin, L.A. Prozorova, M.R. Lees, G. Balakrishan, O.A. Petrenko. Phys. Rev. B 82, 094428-1 (2010).

[15] P. de Réotier Dalmas, A. Yaouanc, Y. Chapuis, S.H. Curoe, B. Grenier, E. Ressouche, C. Marin, J. Lago, C. Baines, S.R. Gilin. Phys. Rev. B 86, 104424-1 (2012).

[16] Ю.К. Товбин, М.В. Титов, В.Н. Комаров. ФТТ 57, 2, 342 (2015).

[17] L.A. Solovyov. J. Appl. Crystallogr. 37, 743 (2004).

[18] В.М. Денисов, Л.Т. Денисова, Л.А. Иртюго, В.С. Биронт. ФTT 52, 7, 1274 (2010).

[19] Л.Т. Денисова, Л.А. Иртюго, Ю.Ф. Каргин, В.В. Белецкий, В.М. Денисов. Неорган. материалы 53, 1, 71 (2017).

[20] M. Jafar, P. Sengupta, S.N. Achary, A.K. Tyagi. J. Eur. Ceram. Soc. 34, 4373 (2014).

[21] K. Boroudi, B.D. Gaulin, S.H. Lapidus, J. Gaudet, R.J. Cava. Phys. Rev. B. 92, 024110-1 (2015).

[22] В.И. Петьков, Е.А. Асабина, М.В. Суханов, А.В. Маркин, Н.Н. Смирнова. ЖФХ 87, 12, 2000 (2013).

[23] С.М. Скуратов, В.П. Колесов, А.Ф. Воробьев. Термохимия. Изд-во МГУ, М. (1966). Ч. II. 434 с. 